\title{
Metastatic Digestive System Neuroendocrine Neoplasm
}

National Cancer Institute

\section{Source}

National Cancer Institute. Metastatic Digestive System Neuroendocrine Neoplasm. NCI

Thesaurus. Code C156492.

A neuroendocrine neoplasm that arises from any part of the digestive system and has

metastasized to another anatomic site. 